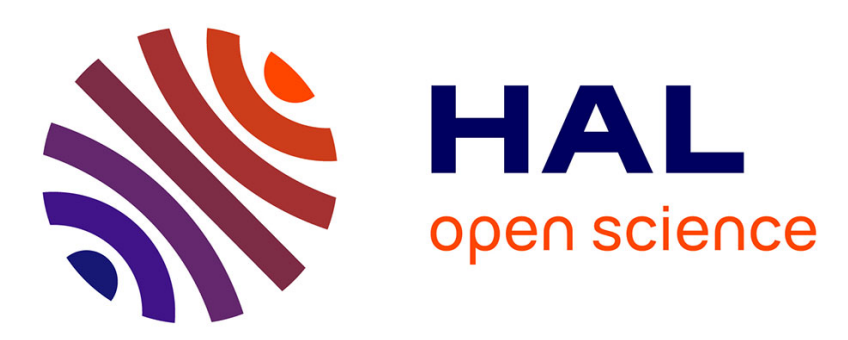

\title{
Asynchrony of actuarial and reproductive senescence: a lesson from an indeterminate grower
}

Hugo Cayuela, Jean-François Lemaître Lemaître, Lorenzo Rugiero, Massimo Capula, Luca Luiselli

\section{- To cite this version:}

Hugo Cayuela, Jean-François Lemaître Lemaître, Lorenzo Rugiero, Massimo Capula, Luca Luiselli. Asynchrony of actuarial and reproductive senescence: a lesson from an indeterminate grower. Biological Journal of the Linnean Society, 2020, 131 (3), pp.667-672. 10.1093/biolinnean/blaa127 . hal-03060309

\section{HAL Id: hal-03060309 \\ https://hal.science/hal-03060309}

Submitted on 14 Dec 2020

HAL is a multi-disciplinary open access archive for the deposit and dissemination of scientific research documents, whether they are published or not. The documents may come from teaching and research institutions in France or abroad, or from public or private research centers.
L'archive ouverte pluridisciplinaire HAL, est destinée au dépôt et à la diffusion de documents scientifiques de niveau recherche, publiés ou non, émanant des établissements d'enseignement et de recherche français ou étrangers, des laboratoires publics ou privés. 


\section{Asynchrony of actuarial and reproductive senescence: a lesson from an}

\section{2 indeterminate grower}

3 Hugo Cayuela ${ }^{1}$, Jean-François Lemaitre ${ }^{2}$, Lorenzo Rugiero ${ }^{3}$, Massimo Capula ${ }^{4}$, Luca Luiselli3 ${ }^{3,5,6}$

4

$5 \quad{ }^{1}$ Département de Biologie, Institut de Biologie Intégrative et des Systèmes (IBIS), Université

6 Laval, Pavillon Charles-Eugène-Marchand, Québec, QC G1V 0A6, Canada

$7 \quad{ }^{2}$ Université Lyon 1, CNRS, UMR 5558, Laboratoire de Biométrie et Biologie Evolutive, F-

8 69622, Villeurbanne, France

$9 \quad{ }^{3}$ Institute for Development, Ecology, Conservation and Cooperation, via G. Tomasi di

10 Lampedusa 33, I-00144 Rome, Italy

$11{ }^{4}$ Museo Civico di Zoologia, Rome, Italy

$12{ }^{5}$ Department of Applied and Environmental Biology, Rivers State University of Science and

13 Technology, P.M.B. 5080 Nkpolu, Port Harcourt, Rivers State, Nigeria

$14{ }^{6}$ University of Lomé, Faculty of Sciences, Department of Zoology, BP: 6057 Lome Togo

16 Running head: Senescence in an indeterminate grower

17

18 Abstract

19

20 Aging evolutionary theories predict that patterns of actuarial and reproductive senescence should

21 be aligned, with a common onset of senescence set at the age of first reproduction. However, a few

22 empirical studies reported asynchrony between actuarial and reproductive senescence. This

23 asynchrony is expected to be particularly pronounced in organisms with indeterminate growth. Yet,

24 this process is still poorly documented due to the lack of long-term demographic data on known-

25 aged individuals. We investigated the asynchrony of actuarial and reproductive senescence in the 
44 Although a few studies have challenged the idea of an inevitable senescence in nature (e.g. Martinez 45 1998, Cayuela et al. 2020), it is now broadly recognized that senescence, the decline in the 46 contribution to fitness with increasing age, is a widespread phenomenon across the animal kingdom

47 (Nussey et al. 2013; Gaillard \& Lemaître 2020). Senescence can be due to an age-specific decrease 48 in survival probabilities (i.e., actuarial senescence) and/or reproductive performance (i.e., 49 reproductive senescence), two processes usually anchored in the same theoretical framework 50 (Gaillard \& Lemaitre 2017). Evolutionary theories predict that patterns of actuarial and 51 reproductive senescence should be aligned (Williams 1957, Maynard-Smith 1962), with a common 52 onset of senescence at the age of first reproduction (Williams 1957). However, few recent studies, 53 performed in both laboratory and free-ranging conditions, reported asynchrony between actuarial 54 and reproductive senescence patterns (reviewed in Gaillard \& Lemaitre 2017). The factors 55 modulating the degree of synchrony are still poorly understood.

56 The asynchrony between actuarial and reproductive senescence could be particularly 57 pronounced in organisms with indeterminate (i.e., continuous) growth (e.g., fishes, amphibians, 58 and reptiles) where survival and reproductive traits (e.g., fecundity, offspring survival) are often 59 positively correlated with maternal body size, and thus indirectly determined by female age 60 (Hoekstra at al. 2020). This asynchrony could result from non-linear relationships between fitness 61 components and age. The fecundity of females with indeterminate growth recurrently increases 62 with body size and age in a linear way (e.g., in reptiles, Jenkins et al. 2009, Setser et al. 2010, Rose 63 et al. 2018), whereas the strength and the form of the relationship between mortality and age after 64 sexual maturity can be highly variable among species (Colchero et al. 2019, Cayuela et al. 2019a) 65 and populations (Cayuela et al. 2020).

66 To date, the asynchrony of actuarial and reproductive senescence in indeterminate growers 67 is still poorly documented, mainly due to the lack of long-term demographic data on known-aged 
94 day lasting from 0800 to 1800 ), by two or three people who searched intensively for snakes in the

95 dilapidated building and neighbouring area of about $100 \times 80 \mathrm{~m}$. Snakes were captured by hand,

96 and individually marked by ventral scale clipping for future identification. At their first capture,

97 female snakes were measured for snout-vent-length (SVL). We did not measure them on further

98 captures to minimize disturbance and hence risks of their departure from the nesting area, as

99 permanent emigration would bias capture-recapture inferences. We were able to assess the age of

10016 females that were captured at juvenile stage over the capture-recapture survey. Detailed

101 information about the number of captures performed each year is given in Table $\mathbf{S 1 .}$

102 Several females $(\mathrm{N}=16)$ on their first capture were palpated in the abdomen to verify their

103 pregnancy status and to count the number of eggs (Filippi et al. 2007). We also captured 44

104 additional females in the surroundings of the study area to increase the number of observations of

105 egg clutch size $(\mathrm{N}=60$ in total $)$.

106

107

Reproductive senescence: assessing age-dependent variation in clutch size

108

109 First, we verified that SVL was a good proxy of female age by quantifying the correlation between 110 age and SVL in a small set of females for which the age was known $(\mathrm{N}=16)$. Then, we examined 111 how annual egg clutch size was associated with SVL in a larger sample of females $(\mathrm{N}=60)$. In 112 both cases, we used regression models where SVL or egg clutch size were included as the response 113 variable and body size or age were included as explanatory variables. We compared null (i.e. 114 without covariate), linear, and polynomial models using their AIC. We graphically verified the fit 115 of the model by examining model residuals. The analyses were conducted in $\mathrm{R}$ program ( $\mathrm{R}$ 116 Development Core Team 2018). 
149 Our results confirmed that female SVL linearly increased with age (Fig.1A and Table S2 for model 150 selection procedure) and was thus a robust proxy of their age $\left(R^{2}=0.43\right)$. Next, we showed that 151 annual egg clutch size increased with SVL (Fig.1B). Although the polynomial model was close 152 (less than 2 AIC points between the two models), the linear model was selected $R^{2}(0.74)$ (Table 153 S3). Overall, our analyses highlighted that female annual fecundity increased linearly with SVL 154 and age.

BaSTA models revealed that capture-recapture data were best described by a logistic function 159 without any refinement of the shape (Table 1). The cumulative probability of surviving was 0.75 160 until age six, 0.50 until age seven, and 0.25 until age eight (Fig.1C). Furthermore, the model 161 showed a strong positive effect of age on hazard rate (Fig.1D), which indicates an early and strong 162 actuarial senescence in $H$. viridiflavus.

\section{Discussion}

166 Using capture-recapture data collected over a 29-year period, we showed that $H$. viridiflavus female 167 did not experience any fecundity loss late in life, suggesting a negligible reproductive senescence. 168 In contrast, they suffered from an early and severe actuarial senescence. Taken together, those 169 results revealed a pronounced asynchrony in the senescence process of two main fitness 170 components. 
197 general inferences about the ecological and biological factors modulating the asynchrony between

198 aging components. At the intraspecific level, abiotic factors such as temperature and habitat 199 predictability regulate lifespan and actuarial senescence (Sears 2005, Hjernquist et al. 2012, Zhang 200 et al. 2018, Cayuela et al. 2019b), as well as reproductive investment (Morrison et al. 2003, Cayuela 201 et al. 2016, Hughes et al. 2019), in ectotherm vertebrates with an indeterminate growth, which could 202 ultimately modify the asynchrony of senescence patterns. In our study system, the low abundance 203 of natural predators compared to other habitats occupied by H. viridiflavus (Philippi et al. 2007) 204 could also buffer actuarial senescence by reducing predation-induced mortality late in life, which 205 might lead to intraspecific variation in the degree of asynchrony between aging components. 206 Furthermore, covariation between mortality patterns and several phenotypic traits of indeterminate 207 growers could result in interspecific variation in the asynchrony of actuarial and reproductive 208 senescence. In particular, the magnitude of the asynchrony could be diminished in species with 209 size-dependent fecundity and negligible or even "negative" actuarial senescence (sensu Vaupel et 210 al. 2004, Jones \& Vaupel 2017) allowed by high regeneration capacities (e.g., salamanders, Cayuela 211 et al. 2019a), or chemical (e.g., venomous snakes, Cayuela et al. 2019a, Colchero et al. 2019) and 212 armour protection (e.g., turtles, Warner et al. 2016). Overall, our study raises important questions 213 about the ecological and evolutionary mechanisms allowing the uncoupling of reproductive and 214 actuarial senescence processes.

216 Acknowledgments

217 We thank Christopher R. Friesen and two other anonymous reviewers for their helpful comments. 218 219 References 
246 Du, W., Ji, X., \& Shine, R. (2005). Does body-volume constrain reproductive output in lizards?.

247 Biology Letters, 1, 98-100.

248 Filippi, E., Anibaldi, C., Capizzi, D., Ceccarelli, A., Capula, M. \& Luiselli, L. (2007). Long-term 249 fidelity to communal oviposition sites in Hierophis viridiflavus. Herpetological Journal 17, 7$250 \quad 13$.

251 Fornasiero, S., Bonnet, X., Dendi, F., \& Zuffi, M. A. (2016). Growth, longevity and age at maturity 252 in the European whip snakes, Hierophis viridiflavus and H. carbonarius. Acta Herpetologica, $253 \quad 11,135-149$.

254 Gaillard, J. M., \& Lemaître, J. F. (2017). The Williams' legacy: A critical reappraisal of his nine 255 predictions about the evolution of senescence. Evolution, 71, 2768-2785.

256 Gaillard, J. M., \& Lemaître, J. F. (2020). An integrative view of senescence in nature. Functional 257 Ecology, 34, 4-16.

258 Gompertz, B. (1825) On the nature of the function expressive of the law of human mortality, and 259 on a new mode of determining the value of life contingencies. Philosophical Transactions of the $260 \quad$ Royal Society of London, 115, 513-583.

261 Hjernquist, M. B., Söderman, F., Jönsson, K. I., Herczeg, G., Laurila, A., \& Merilä, J. (2012). 262 Seasonality determines patterns of growth and age structure over a geographic gradient in an 263 ectothermic vertebrate. Oecologia, 170, 641-649.

264 Hoekstra, L. A., Schwartz, T. S., Sparkman, A. M., Miller, D. A., \& Bronikowski, A. M. (2020). 265 The untapped potential of reptile biodiversity for understanding how and why animals age. $266 \quad$ Functional Ecology, 34, 38-54.

267 Hughes, D. F., Meshaka Jr, W. E., Lieb, C. S., \& Pechmann, J. H. (2019). Latitudinal variation in 268 life history reveals a reproductive advantage in the Texas Horned Lizard (Phrynosoma 269 cornutum). Copeia, 107, 736-747. 
Rose, J. P., Ersan, J. S., Wylie, G. D., Casazza, M. L., \& Halstead, B. J. (2018). Reproductive 296 frequency and size-dependence of fecundity in the giant gartersnake (Thamnophis gigas). 297 Herpetological Conservation and Biology, 13, 80-90.

298 Sears, M. W. (2005). Geographic variation in the life history of the sagebrush lizard: the role of 299 thermal constraints on activity. Oecologia, 143, 25-36.

300 Setser, K., Mociño-Deloya, E., Pleguezuelos, J. M., Lazcano, D., \& Kardon, A. (2010). 301 Reproductive ecology of female Mexican lance-headed rattlesnakes. Journal of Zoology, 281, 302 175-182.

303 Shine, R. (2003). Reproductive strategies in snakes. Proceedings of the Royal Society of London. 304 Series B: Biological Sciences, 270, 995-1004.

305 Siler, W., (1979). A competing-risk model for animal mortality. Ecology, 60, 750-757.

306 Sparkman, A. M., Arnold, S. J., \& Bronikowski, A. M. (2007). An empirical test of evolutionary 307 theories for reproductive senescence and reproductive effort in the garter snake Thamnophis 308 elegans. Proceedings of the Royal Society B: Biological Sciences, 274, 943-950.

309 Spiegelhalter, D. J., Best, N. G., Carlin, B. P., \& Van Der Linde, A. (2002). Bayesian measures of 310 model complexity and fit. Journal of the Royal Statistical Society: Series B, 64, 583-639.

311 Stanford, K. M., \& King, R. B. (2004). Growth, survival, and reproduction in a northern Illinois 312 population of the plains gartersnake, Thamnophis radix. Copeia, 2004, 465-478.

313 Vaupel, J., Manton, K., \& Stallard, E. (1979). The impact of heterogeneity inindividual frailty on 314 the dynamics of mortality. Demography, 16, 439-454. URL http://www.jstor.org/stable/206122

315 Vaupel, J. W., Baudisch, A., Dölling, M., Roach, D. A., \& Gampe, J. (2004). The case for negative 316 senescence. Theoretical population biology, 65, 339-351.

317 Warner, D. A., Miller, D. A., Bronikowski, A. M., \& Janzen, F. J. (2016). Decades of field data 318 reveal that turtles senesce in the wild. Proceedings of the National Academy of Sciences, 113, $319 \quad 6502-6507$. 

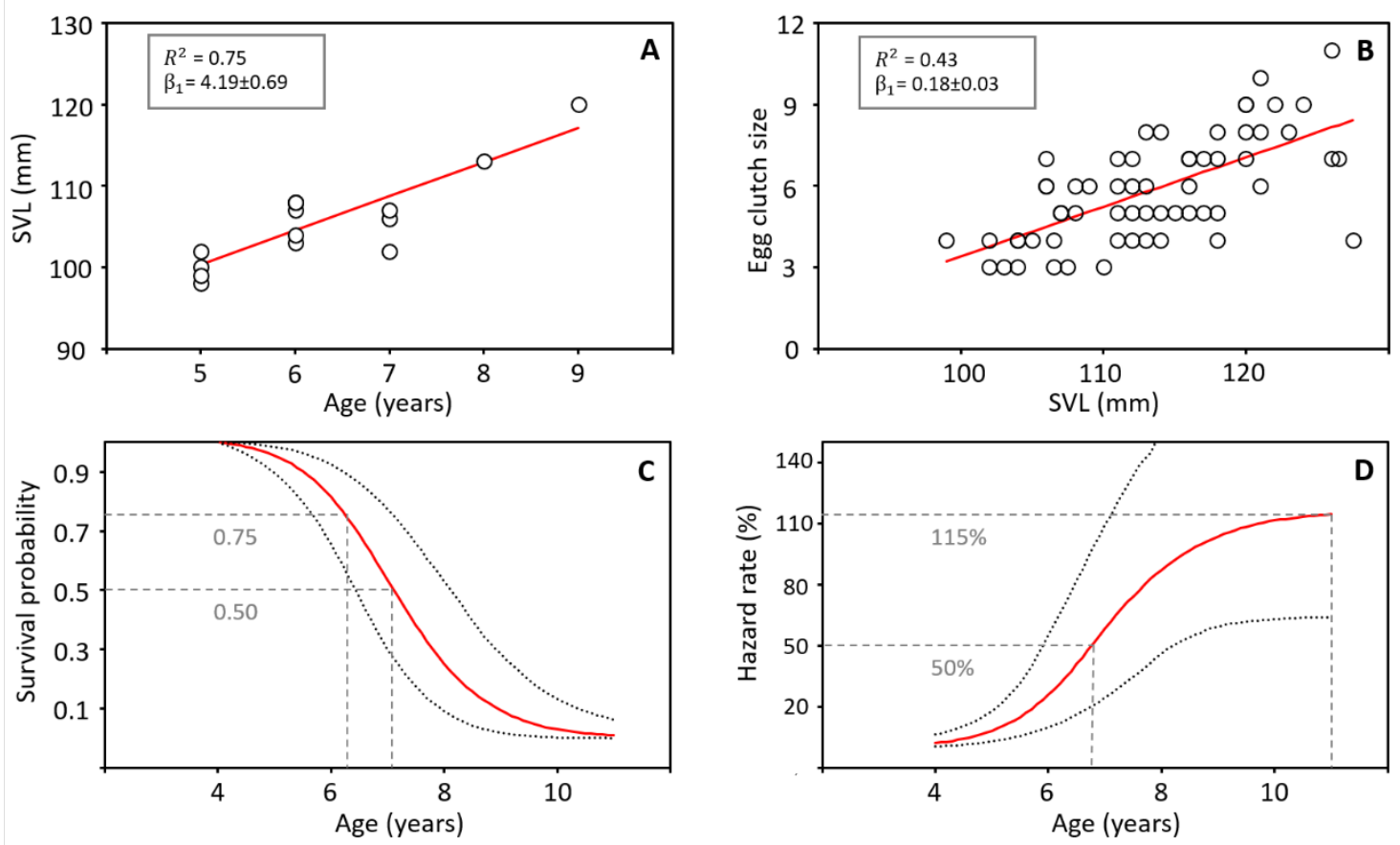

330 Fig.1. Reproductive and actuarial senescence in females of Hierophis viridiflavus. (A) Linear 331 relationship between snout-vent-length (SVL) and age. (B) Linear relationship between egg clutch 332 size and SVL. (C) Relationship between survival and age described by a logistic function. (D) 333 Relationship between hazard rate and age described by a logistic function. 